\title{
Use of a triplex polymerase chain reaction for the detection and differentiation of Mycoplasma pneumoniae and Mycoplasma genitalium in the presence of human DNA
}

\author{
Nathalie Cadieux, ${ }^{1} \uparrow$ Pierre Lebel $^{2}$ and Roland Brousseau ${ }^{1 *}$ \\ ${ }^{1}$ Molecular Biology Sector, Biotechnology Research Institute, 6100 Royalmount Avenue, Montreal, Quebec, \\ Canada H4P 2R2 \\ ${ }^{2}$ Department of Microbiology and Immunology, Sainte-Justine Hospital, 3175 Côte Sainte-Catherine, Montreal, \\ Quebec, Canada H3T 1C5
}

(Received 12 January 1993; revised 31 March 1993; accepted 21 April 1993)

\begin{abstract}
PCR primers corresponding to the adhesin genes of Mycoplasma pneumoniae and Mycoplasma genitalium were shown to detect the corresponding organisms specifically. Absence of cross-reaction with seven other mollicute species and six unrelated bacterial species commonly found in humans was demonstrated. Positive control primers directed against human mitochondrial DNA could be mixed with the Mycoplasma primers without loss of specificity or sensitivity. A detection level of 10 c.f.u. of either Mycoplasma species could be readily obtained, even in the presence of $10^{4}$ human cells. The triplex PCR method developed is very simple and does not require hybridization or the use of radioisotopes and allows detection and differentiation of these mycoplasmas against the background of human DNA found in clinical specimens.
\end{abstract}

\section{Introduction}

Mycoplasma pneumoniae is the aetiological agent of many respiratory infections among which primary atypical pneumonia is the most important (Couch, 1990). This micro-organism is presently responsible for $10-20 \%$ of all radiographically-proven pneumonias and up to $25 \%$ of all paediatric primary atypical pneumonias (Cherry, 1987). Erythromycin or a tetracycline is generally used to treat these infections and such treatment significantly reduces the duration of illness (Shames et al., 1970). Thus, the main problem with $M$. pneumoniae pneumonia is not treatment, but diagnosis which is presently inadequate.

Culture of $M$. pneumoniae is expensive, time consuming, labour intensive and generally of retrospective value only, as it can take up to 6 weeks before becoming positive (Tully \& Razin, 1983). Serological methods are more extensively used than culture because they are easier to perform and more affordable. However, they are also generally non-specific (Clyde et al., 1984),

\footnotetext{
*Author for correspondence. Tel. (514) 496 6152; fax (514) 496 6213.

$\dagger$ Present address: Health and Welfare Canada, Health Protection Branch Building 7, Tunney's Pasture, Ottawa, Ontario, Canada K1A 0L2.
}

insensitive and retrospective. Diagnosis is further complicated by the possible presence of $M$. genitalium which shares many antigens with $M$. pneumoniae (Lind, 1982; Lind et al., 1984; Tully, 1989) and cannot be differentiated from it by culture. Since $M$. genitalium was first isolated from men with non-gonococcal urethritis (Tully et al., 1981), its cross-reactivity with $M$. pneumoniae was initially of little concern in the diagnosis of $M$. pneumoniae pneumonia. However, $M$. genitalium may be isolated from respiratory tract samples (Baseman et al., 1988), and its possible presence should always be considered when trying to diagnose a potential $M$. pneumoniae pneumonia (Tully, 1989); previously, many $M$. genitalium isolates might have been wrongly identified as $M$. pneumoniae.

Recently, DNA probes have been used for the diagnosis of $M$. pneumoniae infections (Hyman et al., 1987; Göbel et al., 1987; Dular et al., 1988; Hata et al., 1990; Kleemola et al., 1990), but they are usually insensitive (Bernet et al., 1989) and hard to handle in a diagnostic laboratory because they are generally radiolabelled, which introduces problems of safety and limited shelf life (Dular et al., 1988; Kleemola et al., 1990). Furthermore, they are often unable to differentiate $M$. pneumoniae and $M$. genitalium, unless specifically designed for this purpose (Dular et al., 1988; Hata et al., 1990; Kleemola et al., 1990). 
Presently, the polymerase chain reaction (PCR) is the most promising method for the diagnosis of $M$. pneumoniae pneumonias, as it is rapid, extremely sensitive and can be designed to be specific (Peter, 1991). It can also be used without radioisotopic labelling. It is, however, susceptible to artifacts, of which the most serious with regards to diagnostic tests are the occurrence of false positives, usually through sample contamination, or false negatives, through the presence of inhibitors that prevent DNA amplification (Erlich, 1989).

The main goal of our study was to design a rapid, sensitive and specific PCR test that could eventually be used to detect and differentiate $M$. pneumoniae and $M$. genitalium directly in clinical specimens, without the need for hybridization or radioisotopes. We also investigated the inclusion of primers in the assay procedure that could amplify a fragment of human DNA as an internal positive control to validate both the PCR process and the sampling procedure (Keller et al., 1990). Finally, we wanted to optimize the PCR conditions to perform the entire test in the same tube; it would then be a triplex PCR.

\section{Methods}

Bacterial strains and culture procedure. The following mycoplasma strains were used and were purchased from the American Type Culture Collection (ATCC, Rockville, MD, USA): Mycoplasma pneumoniae ATCC $15531, M$. pneumoniae ATCC 29342, $M$. genitalium ATCC $33530, M$. buccale ATCC 23636, $M$. salivarium ATCC 23064, $M$. orale ATCC 23714, M. fermentans ATCC 19989, M. hominis ATCC 23114, Acholeplasma laidlawii ATCC 23206 and Ureaplasma urealyticum ATCC 27618. All mycoplasma strains were cultured in diphasic SP-4 medium (Tully et al., 1977) containing 2000 units penicillin $\mathrm{G} \mathrm{ml}^{-1}$, 500 units polymyxin $\mathrm{B} \mathrm{ml}^{-1}$ and $2.5 \mu \mathrm{g}$ amphotericin $\mathrm{B} \mathrm{ml}^{-1}$, as described by Razin \& Tully (1983). Thallium acetate was not added to the medium since it can inhibit growth of M. genitalium (Razin \& Tully, 1983). The medium was further supplemented with glucose $(0.5 \%)$, arginine $(0.25 \%)$ or urea $(0.5 \%)$ depending on the nutritional needs of the species being cultivated. Unrelated bacterial species, obtained from Ste-Justine's hospital (Montreal, Quebec, Canada), were: Escherichia coli ATCC 25922, Staphylococcus aureus ATCC 29213 and Pseudomonas aeruginosa ATCC 27853. A fresh Streptococcus pneumoniae clinical isolate was used because no ATCC strain was available at the time of study. Additional bacterial species, Branhamella catarrhalis ATCC 25238 and Haemophilus influenzae ATCC 33391, were obtained from the Biotechnology Research Institute (Montreal, Quebec, Canada). $E$. coli and $P$. aeruginosa were grown in $2 \times \mathrm{YT}$ broth (Sambrook et al., 1989), Staph. aureus and B. catarrhalis were grown in trypticase soy broth (BBL) and Strep. pneumoniae and $H$. influenzae were grown in brain heart infusion with haemin (Difco).

Clinical samples. Throat swabs were collected in $1 \mathrm{ml} \mathrm{SP}-4$ broth and immediately sent to the laboratory, on ice. They were processed upon arrival, or after storage at $-70^{\circ} \mathrm{C}$. A portion of the sample $(100 \mu)$ was inoculated onto a SP-4 agar plate which was regularly observed microscopically, over 3 weeks, for the appearance of typical mycoplasma colonies. At the same time, half of the remaining volume was inoculated into a vial of diphasic SP-4 medium which was regularly observed for $\mathrm{pH}$ change for 6 weeks, and subcultured on to SP-4 agar every week. Potential $M$. pneumoniae or $M$. genitalium colonies were tested by haemadsorption and haemolysis (Razin \& Tully, 1983). In paraliel, the other half of the remaining volume was prepared for PCR, as described below. Other clinical specimens were processed as described for throat swabs except that $10^{-1}$ and $10^{-2}$ dilutions were also inoculated into diphasic SP-4 medium, to prevent overgrowth of contaminating micro-organisms or the inhibition of mycoplasmal growth by components of the clinical sample.

DNA extraction and sample preparation for PCR. DNA from different mycoplasma strains and clinical samples was prepared for PCR as follows: the sample was centrifuged at 14000 r.p.m. for 20 min, washed in PBS (0.1 M-NaCl, 2.5 mM-KCl, $10 \mathrm{~mm}-\mathrm{Na}_{2} \mathrm{HPO}_{4}, 1.5 \mathrm{~mm}-$ $\mathrm{KH}_{2} \mathrm{PO}_{4}, \mathrm{pH} 7.4$ ) and resuspended in $60 \mu \mathrm{l}$ distilled water. The sample was then boiled for $5-10 \mathrm{~min}$ and stored at $4{ }^{\circ} \mathrm{C}$.

Primers. The three pairs of primers used in this study were synthesized on an Applied Biosystems 380A DNA synthesizer by the phosphoramidite method. The pair P4 (P4A : $5^{\prime}$ AGG CTC AGG TCA ATC TGG CGT GGA $3^{\prime}$ and P4B: $5^{\prime}$ GGA TCA AAC AGA TCG GTG ACT GGG T $3^{\prime}$ ) was specific to the $M$. pneumoniae P1 adhesin gene and amplified a 345 bp fragment from nucleotides 3947 to 4291 (GenBank accession no. M18639). The pair G3 (G3A: 5' GCT TTA AAC CTG GTA ACC AGA TTG ACT $3^{\prime}$ and G3B: $5^{\prime}$ GAG CGT TAG AGA TCC CTG TTC TGT TA $3^{\prime}$ ) was specific to the $M$. genitalium adhesin gene and amplified a $507 \mathrm{bp}$ fragment from nucleotides 3754 to 4260 (GenBank accession no. M31431). The pair H6 (H6A: 5' ATG ACC CAC CAA TCA CAT GCC TAT CA $3^{\prime}$ and H6B: $5^{\prime}$ ACT AGT TAA TTG GAA GTT AAC GGT ACT A 3') was specific to the human mitochondrial cytochrome oxidase subunit 3 gene (GenBank accession nos J014125, M12548, M58503, M63932 and M63933) and amplified a 828 bp fragment from nucleotides 9207 to 10034 which was used as an internal positive control. The primers were chosen to have a high but equal normalized length $\left(L_{\mathrm{n}}\right)$ (Wu et al., 1991) to allow the use of a high annealing temperature which would reduce the possibility of obtaining unwanted bands originating from non-specific amplification.

PCR amplification and electrophoresis. PCR reactions were performed in a total volume of $50 \mu \mathrm{l}$ containing $5 \mu 110 \times$ PCR buffer (100 mM-Tris/ $\mathrm{HCl} \mathrm{pH} \mathrm{8.3,} 500 \mathrm{~mm}-\mathrm{KCl}, 27 \mathrm{~mm}-\mathrm{MgCl}_{2}, 0 \cdot 1 \%$ gelatin), $250 \mu \mathrm{M}$ of each dNTP (Pharmacia), 0.5-1.5 $\mu \mathrm{M}$ (depending on the pair of primers used) of each primer, 2 units of Taq DNA polymerase (Pharmacia), and an appropriate volume (5 or $25 \mu \mathrm{l}$ of a clinical sample or a volume corresponding to $10^{4}$ bacterial or human cells) of the sample to be amplified. The reaction volume was overlaid with $50 \mu \mathrm{l}$ paraffin oil to prevent evaporation. The samples were placed in a thermal cycler (Perkin Elmer-Cetus model TC-1) and submitted to 30 cycles of amplification. One such cycle consisted of denaturation at $94{ }^{\circ} \mathrm{C}$ for $1 \mathrm{~min}$, annealing at $65^{\circ} \mathrm{C}$ for $1 \mathrm{~min}$ and elongation at $72{ }^{\circ} \mathrm{C}$ for $1 \mathrm{~min}$. After the last cycle, the samples were kept at $72^{\circ} \mathrm{C}$ for an additional $10 \mathrm{~min}$ to ensure that the polymerization of every fragment was complete. The samples were then kept at $4{ }^{\circ} \mathrm{C}$ until analysed on a $1.5 \%$ (w/v) agarose gel (SeaKem LE, FMC BioProducts). The gel was run in TAE buffer at $10 \mathrm{~V} \mathrm{~cm}^{-1}$ for $1-1.5 \mathrm{~h}$ and then stained with a solution of $500 \mu \mathrm{g}$ ethidium bromide $\mathrm{I}^{-1}$ before being photographed with a Polaroid MP-4 camera.

Southern blotting and hybridization. To verify that the fragments amplified by the pairs of primers P4, G3 and $\mathrm{H} 6$ were the ones expected, oligonucleotides specific to internal regions of those fragments were synthesized and used as probes to hybridize Southern blots. Probe 4A4B was specific to the $345 \mathrm{bp}$ fragment of $M$. pneumoniae DNA amplified by the P4 primers and had the sequence 5' GAT GTT GAT GGT ATT GAT C 3'. Probe 3A3B was specific to the $507 \mathrm{bp}$ fragment of $M$. genitalium DNA amplified by the $\mathrm{G} 3$ primers and had the sequence 5' CCT TTG ATT GTA ACT GTT C 3'. Finally, probe 
6A6B was specific to the 828 bp fragment of human DNA amplified by the H6 primers and had the sequence 5' AGA AAA CAA CCG AAA CCA A $3^{\prime}$. The probes were radiolabelled at their $5^{\prime}$ end with T4 polynucleotide kinase (Pharmacia) and $\left[\gamma^{32} \mathrm{P}\right] \mathrm{ATP}$. The capillary transfer of the DNA on to nitrocellulose membranes (Ba-85, Schleicher \& Schuell) was done by the Southern method (Sambrook et al., 1989) except that the denaturing and neutralizing solutions contained $0-15 \mathrm{M}-$ $\mathrm{NaCl}$. Prehybridizations and hybridizations were performed as follows. The nitrocellulose membranes were prehybridized in $6 \times \mathrm{SSC}, 0.5 \%$ Triton X-100, $1 \times$ Denhart's reagent, $3 \%(w / v)$ dextran sulphate at $42{ }^{\circ} \mathrm{C}$ for $1 \mathrm{~h}$. The probe was then added and hybridization performed at $42{ }^{\circ} \mathrm{C}$ for $2 \mathrm{~h}$. After three washes in $3 \times \mathrm{SSC}, 0.5 \%$ Triton X-100 at $42{ }^{\circ} \mathrm{C}$ for $15-30 \mathrm{~min}$, the membranes were autoradiographed on X-ray film (Kodak) in a cassette with amplifying screens at $-80^{\circ} \mathrm{C}$ for about $4 \mathrm{~h}$.

\section{Results}

\section{Optimization of the PCR conditions}

In amplifying $M$. pneumoniae, $M$. genitalium and human DNA together in the same tube, the most important variable was the relative concentrations of the different pairs of primers. The longest fragment $(828 \mathrm{bp}$ from human DNA) needed the highest concentration of primers (H6), whereas the shortest fragment (345 bp from $M$. pneumoniae DNA) needed the lowest concentration of primers (P4) to be amplified efficiently. The $M$. genitalium DNA fragment (amplified by the G3 primers) was of intermediate length $(507 \mathrm{bp})$. When an equal concentration of all six primers was used, only the smallest fragment was amplified, whilst the others were undetectable (data not shown). Reliable amplification of all three bands was obtained when the relative concentrations of the different primers were adjusted to $0.5 \mu \mathrm{M}$ for each of the P4 primers, $1.0 \mu \mathrm{M}$ for each of the G3 primers and $1.5 \mu \mathrm{M}$ for each of the $\mathrm{H} 6$ primers. Other variables studied were the $\mathrm{MgCl}_{2}$ concentration, which was established at $2.7 \mathrm{~mm}$ for optimal results (data not shown) and the number of amplification cycles, where it was found that 30 cycles were sufficient for maximum sensitivity.

\section{Specificity of the primers}

To determine the specificity of the experimental design, amplification was performed on $M$. pneumoniae DNA $\left(10^{4}\right.$ c.f.u.) with the P4 primers, the G3 primers and the H6 primers separately (Fig. $1 a$, lanes $2-4$ ). Only the P4 primers amplified the $M$. pneumoniae DNA and the fragment obtained was $345 \mathrm{bp}$ long, as expected. The same experiment was then performed with $10^{4}$ c.f.u. of $M$. genitalium (Fig. 1 $a$, lanes 5-7) and $10^{4}$ human cells (Fig. 1 $a$, lanes 8-10). It was found that only the G3 primers amplified the $M$. genitalium DNA yielding the expected $507 \mathrm{bp}$ fragment and only the H6 primers amplified the human DNA giving rise to the expected
828 bp fragment. We also performed the triplex PCR where $M$. pneumoniae, $M$. genitalium and human DNA were placed in a single tube, mixed with the three pairs of primers and submitted to 30 cycles of PCR. The results show that the three fragments of the expected size were amplified simultaneously (Fig. $1 a$, lane 11), although the yield of each fragment was somewhat reduced when compared to the result where only one pair of primers was used.

To prove that the three fragments obtained were the ones expected, we hybridized them with oligonucleotides specific to their internal regions. The first probe we used
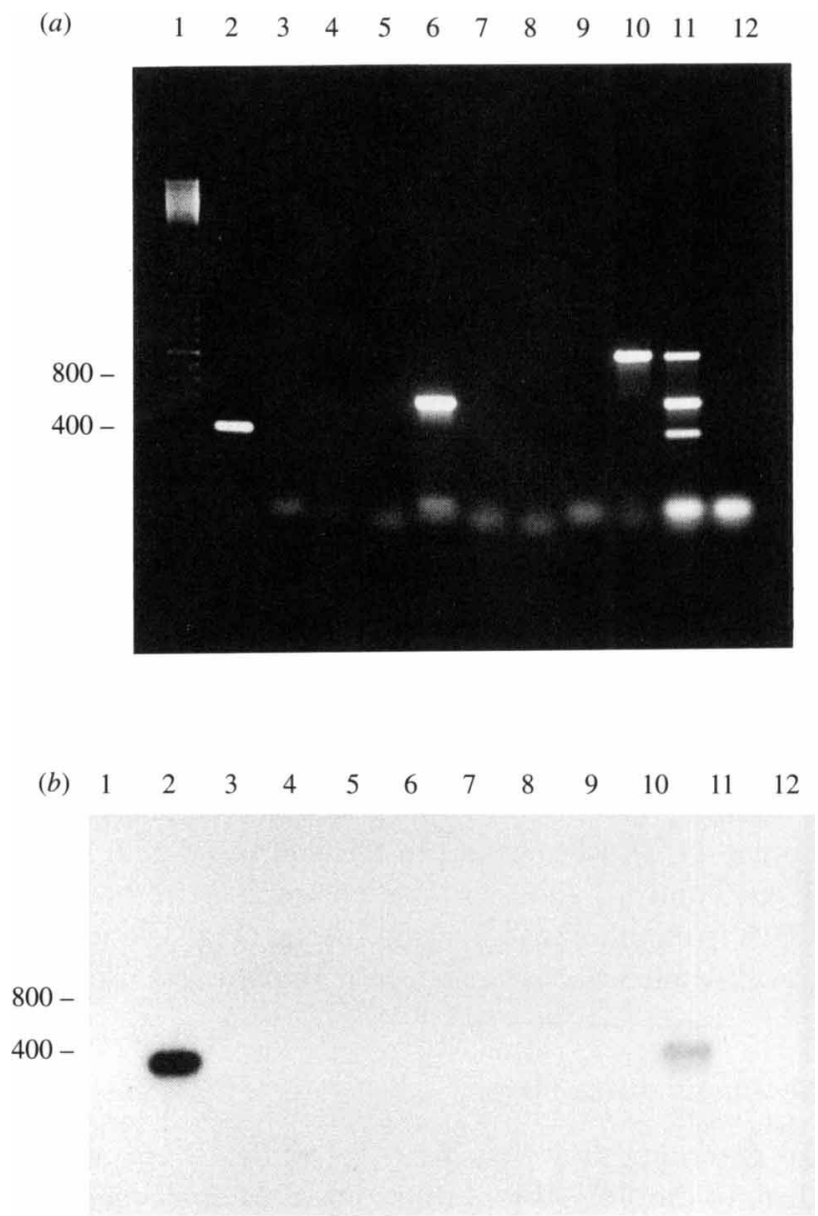

Fig. 1. (a) Specificity of the three pairs of primers tested with $M$. pneumoniae, $M$. genitalium and human DNA. Lane 1: 100 bp ladder (Pharmacia). Lanes 2-4: DNA from $10^{4}$ c.f.u. $M$. pneumoniae ATCC 15531 with $0.5 \mu \mathrm{M} \mathrm{P} 4$ primers (lane 2), $1.0 \mu \mathrm{M}$ G3 primers (lane 3) and $1.5 \mu \mathrm{M}$ H6 primers (lane 4). Lanes 5-7: DNA from $10^{4}$ c.f.u. $M$. genitalium with $0.5 \mu \mathrm{M}$ P4 primers (lane 5), $1.0 \mu \mathrm{M}$ G3 primers (lane 6) and $1.5 \mu \mathrm{M}$ H6 primers (lane 7). Lanes 8-10: DNA from $10^{4}$ human cells with $0.5 \mu \mathrm{M}$ P4 primers (lane 8), $1.0 \mu \mathrm{M}$ G3 primers (lane 9) and $1.5 \mu \mathrm{M} \mathrm{H} 6$ primers (lane 10). Lane 11: all three types of DNA with all three pairs of primers (triplex positive control). Lane 12: no DNA with all three pairs of primers (negative control). (b) Southern blot of the gel from $(a)$ hybridized with the probe 4A4B. Lanes 2 and 11: the probe hybridized to the $345 \mathrm{bp} M$. pneumoniae-specific fragment only. 


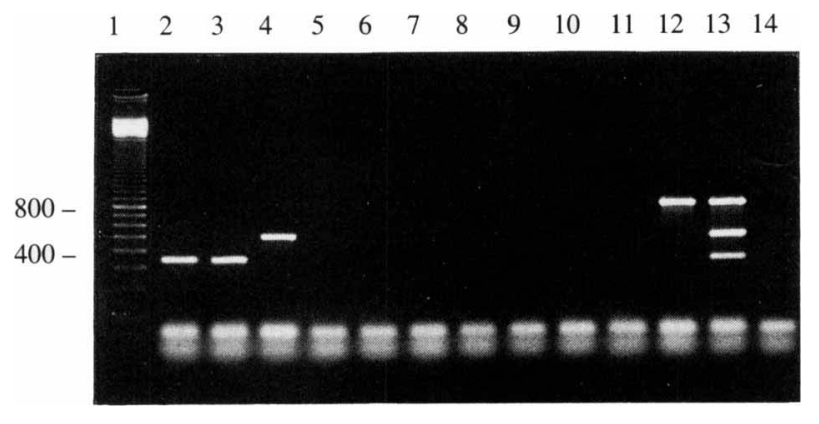

Fig. 2. Specificity of the triplex PCR tested with various mollicute species. Lane 1: $100 \mathrm{bp}$ ladder. Lanes 2-12: 0.5 $\mu \mathrm{M} \mathrm{P4}$ primers, $1.0 \mu \mathrm{M}$ G3 primers and $1.5 \mu \mathrm{M}$ H6 primers with DNA from $10^{4}$ c.f.u. of: $M$. pneumoniae ATCC 15531 (lane 2), M. pneumoniae ATCC 29342 (lane 3), $M$. genitalium (lane 4), $M$. buccale (lane 5), $M$. orale (lane 6), $M$. salivarium (lane 7), $M$. fermentans (lane 8), $M$. hominis (lane 9), Ureaplasma urealyticum (lane 10), Acholeplasma laidlawii (lane 11) and $10^{4}$ human cells (lane 12). Lane 13: $M$. pneumoniae ATCC 15531, $M$. genitalium and human DNA with all three pairs of primers (triplex positive control). Lane 14: no DNA with all three pairs of primers (negative control).

was 4A4B which hybridized to the $345 \mathrm{bp}$ fragment from $M$. pneumoniae that was amplified by the $\mathrm{P} 4$ primers (Fig. 1b, lanes 2 and 11). Similar results were obtained with the probes $3 \mathrm{~A} 3 \mathrm{~B}$ and $6 \mathrm{~A} 6 \mathrm{~B}$, specific to internal regions of the $507 \mathrm{bp}$ fragment from $M$. genitalium and the 828 bp fragment from human DNA, respectively (data not shown).

To assess the specificity of our three pairs of primers, we used them together (Fig. 2), to try to amplify the DNA from the other mollicutes and cell-walled species described in Methods. As expected, fragments were amplified only when $M$. pneumoniae, $M$. genitalium or human DNA was present in the sample (Fig. 2, lanes 2, $3,4,12$ and 13) and there was no amplification when the DNA from other mycoplasma species (Fig. 2, lanes 5-11) or cell-walled bacteria (data not shown) was used.

\section{Sensitivity of the primers}

To determine how sensitive the primers were, we used them to amplify 10 -fold dilutions of $M$. pneumoniae, $M$. genitalium and human DNA to determine the detection limit. In the case of $M$. pneumoniae dilutions amplified with the P4 primers, the DNA from as little as 10 c.f.u. was easily detected (data not shown). On some occasions, DNA from 1 c.f.u. was apparently detected, but that result was not generally reproducible and thus not considered as being the detection limit. Such variability in the results obtained with samples containing DNA from 1 c.f.u. was to be expected. As described by Saiki $e t$ al. (1988), the actual number of target sequences in such a dilution will vary according to a Poisson distribution.
Such a distribution predicts that the probability of a sample containing one or more target sequences is 0.632 when the average number of copies present is 1 per sample. The sensitivity of the G3 primers with dilutions of $M$. genitalium DNA was similar. However, when human DNA was used, the $\mathrm{H} 6$ primers were slightly less sensitive than the $\mathrm{P} 4$ and the G3 primers and about 100 human cells were needed for a visible band to be obtained.

Next, we wanted to see if the detection limit was the same when a fragment was amplified individually or within the triplex PCR. At the same time, we wanted to determine if a very low concentration of one of the targets could be amplified effectively if the two other targets were present at high concentrations. To answer these questions, we tried to amplify 10 -fold dilutions of $M$. pneumoniae DNA in the presence of $10^{4}$ c.f.u. of $M$. genitalium and $10^{4}$ human cells (Fig. $3 a$, lanes 10-16). To be able to make an adequate comparison, we also amplified the same $M$. pneumoniae dilutions individually (Fig. 3a, lanes 2-8). As shown in Fig. 3a, the detection limit for M. pneumoniae DNA was 10 c.f.u. whether the amplification was performed individually or in the triplex PCR (Fig. $3 a$, lanes 5 and 13). Fig. $3 a$ also shows that the sensitivity was not affected by the presence of the two other targets in much higher concentrations, even though the intensity of the $M$. pneumoniae-specific band was a little weaker in the triplex PCR.

Finally, we wanted to determine if the same level of sensitivity could be achieved in a clinical sample. For this purpose, we used nasopharyngeal secretions that were negative for $M$. pneumoniae DNA with the P4 primers, negative for $M$. genitalium DNA with the G3 primers and positive for human DNA with the H6 primers. Tenfold dilutions of $M$. pneumoniae DNA were added and amplification with the $\mathrm{P} 4$ and the $\mathrm{H} 6$ primers performed (Fig. 3b, lanes 10-16). Once again, to be able to make an adequate comparison, the same $M$. pneumoniae dilutions were amplified with the P4 primers only (Fig. $3 b$, lanes 2-8). As determined in the other cases, the detection limit was 10 c.f.u. (Fig. $3 b$, lanes 5 and 13) whether they were amplified individually or in the clinical sample. Amplification of the human DNA present in the clinical sample was not hampered by the presence of the $M$. pneumoniae DNA (Fig. 3b, lanes 10-16).

\section{Clinical samples}

A preliminary study of 30 clinical samples (8 expectorations, 14 throat swabs, 3 nasopharyngeal secretions, 2 bronchoalveolar lavages, 1 bronchial secretions, 1 bronchial lavage and 1 cerebrospinal fluid) was performed. It was sometimes necessary to dilute the sample $1 / 5$ to obtain an amplification because of the presence of 
(a)
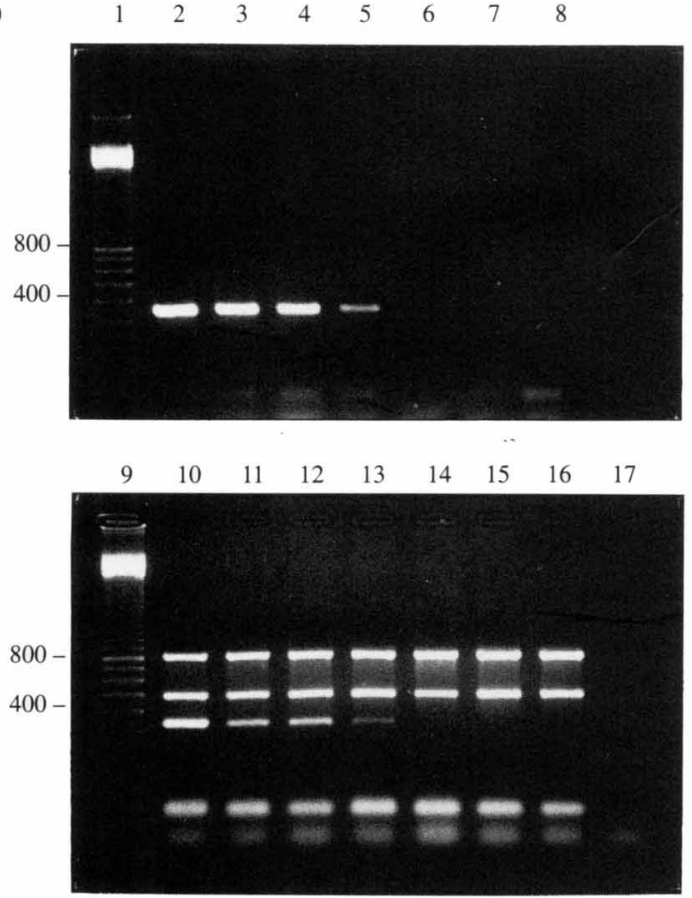

(b) $\quad \begin{array}{llllllll}1 & 2 & 3 & 4 & 5 & 6 & 7 & 8\end{array}$
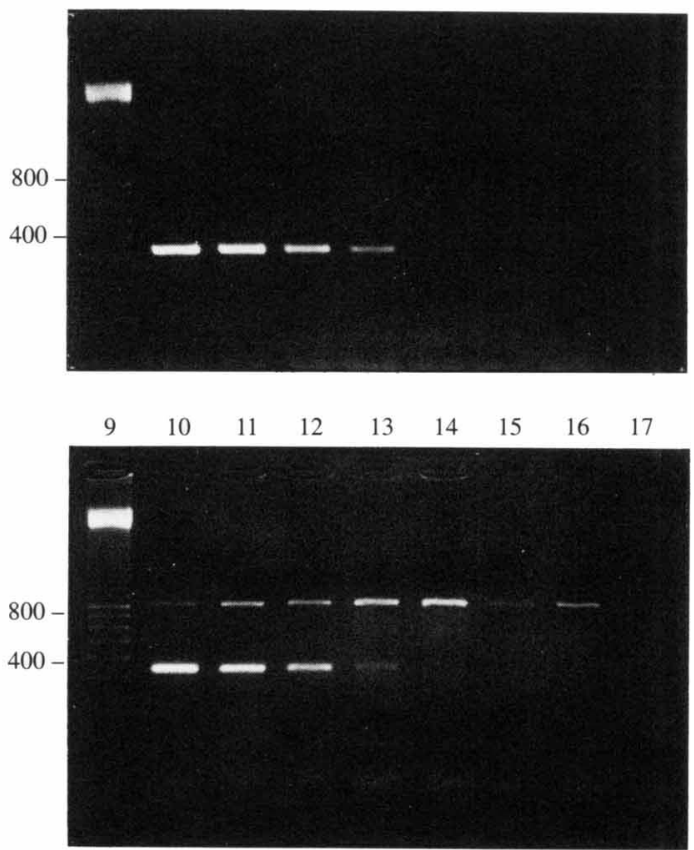

Fig. 3. (a) Sensitivity of the P4 primers with 10-fold dilutions of $M$. pneumoniae DNA tested in the triplex PCR. Lanes 1 and 9: 100 bp ladder. Lanes 2-8: 0.5 $\mu \mathrm{M}$ P4 primers with DNA from $10^{4}$ (lane 2) to $10^{-2}$ (lane 8) c.f.u. M. pneumoniae ATCC 15531. Lanes 10-16: $0.5 \mu \mathrm{M}$ P4 primers, $1.0 \mu \mathrm{M} \mathrm{G} 3$ primers and $1.5 \mu \mathrm{M} \mathrm{H6}$ primers with DNA from $10^{4}$ c.f.u. $M$. genitalium, $10^{4}$ human cells and DNA from $10^{4}$ (lane 10) to $10^{-2}$ (lane 16) c.f.u. M. pneumoniae ATCC 15531. Lane 17: no DNA with all three pairs of primers (negative control). (b) Sensitivity of the P4 primers with 10-fold dilutions of $M$. pneumoniae DNA added to a clinical sample. Lanes 1 and 9: $100 \mathrm{bp}$ ladder. Lanes 2-8: 0.5 $\mu \mathrm{M} \mathrm{P4}$ primers with DNA from $10^{4}$ (lane 2) to $10^{-2}$ (lane 8) c.f.u. $M$. pneumoniae ATCC 15531. Lanes 10-16: $5 \mu$ of the clinical sample with $0.5 \mu \mathrm{M} \mathrm{P4}$ primers, $1.5 \mu \mathrm{M} \mathrm{H6}$ primers and DNA from $10^{4}$ (lane 10) to $10^{-2}$ (lane 16) c.f.u. M. pneumoniae ATCC 15531. Lane 17: no DNA and no clinical sample with $0.5 \mu \mathrm{M}$ P4 primers and $1.5 \mu \mathrm{M} \mathrm{H6}$ primers (negative control).

inhibitors despite the boiling of samples during preparation. Thus, samples were always tested undiluted by triplex PCR and then diluted with each pair of primers individually and also in triplex PCR.

Out of the 30 clinical samples so tested, none were positive for $M$. pneumoniae or $M$. genitalium DNA. However, only two were negative for human DNA, a cerebrospinal fluid and a bronchoalveolar lavage which contained little cellular material if any. When cultured, only two samples out of 30 yielded a mycoplasma but neither were $M$. pneumoniae or $M$. genitalium.

The lack of positive results in the limited number of samples available to us is not surprising in view of the low success of previous researchers in detecting $M$. pneumoniae even under epidemic situations in high risk groups (Kleemola et al., 1990).

\section{Discussion}

The methods presently used to diagnose $M$. pneumoniae infections are inadequate because they lack speed, sensitivity and specificity. Since PCR technology can overcome these problems, it is a promising candidate to replace current diagnostic methods. The goal of our study was to design a PCR test that was sensitive, specific, differentiated between $M$. pneumoniae and $M$. genitalium, included an internal positive control, and could be performed in a single tube and used directly on clinical samples.

Several protocols of DNA preparation for PCR amplification use combinations of organic solvent extraction (e.g. chloroform and/or phenol extraction) or treatment with harsh detergents such as SDS. Although these methods may ensure removal of inhibitors, the organic reagents used may themselves interfere with the amplification reaction and the extra manipulations involved in removing reagents increase the potential for sample contamination and loss of DNA through adsorption on tubes or pipettes. Since PCR can be performed on relatively impure DNA, samples used in this study were simply boiled, thus inactivating nucleases and potential inhibitors of the polymerase. Furthermore, the boiling step efficiently liquified viscous clinical samples such as expectorations that would otherwise have been difficult to process without any additional treatment.

In optimizing the conditions for the triplex PCR the relative concentration of the three pairs of primers was 
the most important variable. It appeared that polymerization or annealing of the primers to the largest DNA fragment was inhibited by the presence of the smaller fragments or their primers. This problem is probably at the annealing level because increasing the concentration of primers specific to the longest fragment allows it to be efficiently amplified, whilst amplification of the smallest fragment is unaffected. Other publications have also mentioned this type of problem in multiplex PCR (Bej et al., 1990, 1991). Indeed, when fragments of different lengths are amplified simultaneously, the shorter ones are advantaged and varying the amount of primers can take care of that problem.

To assess the specificity of the primers was a very important part of this study. First, we had to make sure that our primers were specific to their target sequence and did not amplify DNA from other sources, including the targets of the other primers. Next, we also had to verify that their specificity was as satisfactory in the triplex PCR as it was individually. It was possible that, when used together, primers from different pairs could form a new pair and give rise to unwanted secondary bands with $M$. pneumoniae, $M$. genitalium and human DNA or give bands with DNA from other sources. Several pairs of primers had to be tested before the set used in this study was decided upon.

The next important step in our study was to evaluate the sensitivity of the different pairs of primers. When 10fold dilutions of $M$. pneumoniae and $M$. genitalium were amplified with their respective primers, as little as 10 c.f.u. could be detected, which constitutes a very high level of sensitivity. However, when the same experiment was done with dilutions of human DNA, at least 100 cells were needed for an amplification to occur. This lack of sensitivity achieved with the human primers could be due to the formation of secondary structures in the target DNA itself, which could then affect the annealing of the primers to their specific target sequence. However, we did not consider this lower level of detection for the human DNA as constituting a problem, because it reinforced its role as an internal positive control. Indeed, $M$. pneumoniae and $M$. genitalium adhere strongly to epithelial cells and a sample of good quality that has been harvested correctly will contain a considerable number of epithelial cells (Clyde et al., 1984).

Since one of our goals was to use all the primers together in the same tube, we had to see if the sensitivity level achieved with an individual pair of primers would be reduced in the triplex PCR. However, the detection limit was unchanged (with the exception that the intensity of the signal was reduced in the case of the highest DNA dilutions); it seems that as long as the relative concentrations of the different pairs of primers have been adjusted to allow an efficient amplification of all the fragments in the triplex PCR, the initial quantity of each of the targets has very little importance, if any.

Finally, we have shown that the sensitivity of the assay remains unchanged when one of the targets is added to and amplified directly in a clinical sample, which shows that our method of sample preparation by simply boiling does yield DNA suitable to be amplified directly without any further treatment.

A few groups have already demonstrated the ability of PCR technology to detect $M$. pneumoniae added to clinical samples. Bernet et al. (1989) detected between 100 and 1000 c.f.u. in bronchoalveolar lavages and Jensen et al. (1989) less than 40 c.f.u. in throat swabs. Sasaki et al. (1992) were also able to differentiate $M$. pneumoniae and $M$. genitalium in a test that detected 100 $M$. pneumoniae and $1000 \mathrm{M}$. genitalium. Two groups have recently addressed the internal control issue in detecting $M$. pneumoniae by PCR. The first group, Ursi et al. (1992), cloned their PCR fragment in a plasmid and then inserted a piece of foreign DNA in that fragment, to use it as a positive control. The control was important in avoiding false-negative results, which would have otherwise reached a level of $37 \%$. Assay specificity was not addressed but sensitivity was good in that they were able to detect $1 \mathrm{fg}$ of purified $M$. pneumoniae DNA (approximately one genome), but this decreased to $5 \mathrm{fg}$ when their positive control was included. This phenomenon was also observed in our work where the intensity of the amplified bands was less in the triplex than in the simplex PCR. The second group, Skakni et al. (1992), used the primers published by Bernet et al. (1989) to amplify $M$. pneumoniae DNA directly in clinical samples. To achieve maximum sensitivity they followed the PCR amplification by a Southern blot and hybridization with a radiolabelled oligonucleotide. The most interesting part of their study was the use of the human $\beta$-globin gene as a positive control. Such a control is superior to the one used by Ursi et al. (1992) because it indicates if the sample is of good quality. The main drawback is that they tested for the presence of the human $\beta$-globin gene and $M$. pneumoniae in separate tubes, which does not prevent false-negative results due to technical problems present in the sample tube only. Also, while the use of Southern blotting and radiolabelling increases sensitivity, it takes away some of the advantage of the speed and convenience of the PCR method.

In conclusion we have succeeded in establishing a triplex PCR method to determine the presence of $M$. pneumoniae and/or $M$. genitalium in a clinical sample, with an internal positive control designed to verify both the performance of the PCR process and the validity of the sample collected. The protocol reliably detects 10 c.f.u. of either organism without the need for hybridization and radioisotopes. 
This work was supported by a grant from the FCAR (Fonds pour la formation de chercheurs et d'aide à la recherche) which is an organization from the Government of Quebec. This paper is published as NRCC publication no. 33659 .

\section{References}

Baseman, J. B., Dallo, S. F., Tully, J. G. \& Rose, D. L. (1988). Isolation and characterization of Mycoplasma genitalium strains from the human respiratory tract. Journal of Clinical Microbiology 26, 2266-2269.

Bej, A. K., Mahbubani, M. H., Miller, R., DiCesare, J. L., HafF, L. \& AtLAS, R. M. (1990). Multiplex PCR amplification and immobilized capture probes for detection of bacterial pathogens and indicators in water. Molecular and Cellular Probes 4, 353-365.

Bej, A. K., Mahbubani, M. H. \& Atlas, R. M. (1991). Amplification of nucleic acids by polymerase chain reaction (PCR) and other methods and their applications. Critical Reviews in Biochemistry and Molecular Biology 26, 301-334.

Bernet, C., Garret, M., de Barbeyrac, B., Bebear, C. \& Bonnet, J. (1989). Detection of Mycoplasma pneumoniae by using the polymerase chain reaction. Journal of Clinical Microbiology 27, 2492-2496.

CHERRY, J. D. (1987). Mycoplasma and ureaplasma infections. In Textbook of Pediatric Infectious Diseases, 2nd edn., pp. 1896-1924. Edited by R. D. Feigin \& J. D. Cherry. Philadelphia: W. B. Saunders Company.

Clyde, W. A., JR, KenNy, G. E. \& SchaChter, J. (1984). Laboratory diagnosis of chlamydial and mycoplasmal infections. In Cumitech 19. Coordinating editor: W. L. Drew. Washington, DC: American Society for Microbiology.

Couch, R. B. (1990). Mycoplasma diseases. In Principles and Practice of Infectious Diseases, 3rd edn., pp. 1445-1463. Edited by G. L. Mandell, R. G. Douglas \& J. E. Bennett. New York: Churchill Livingstone.

Dular, R., Kajioka, R. \& Kasatiya, S. (1988). Comparison of Genprobe commercial kit and culture technique for the diagnosis of Mycoplasma pneumoniae infection. Journal of Clinical Microbiology 26, 1068-1069.

ERLICH, H. A. (1989). Polymerase chain reaction. Journal of Clinical Immunology 9, 437-447.

GöBel, U. B., Geiser, A. \& Stanbridge, E. J. (1987). Oligonucleotide probes complementary to variable regions of ribosomal RNA discriminate between Mycoplasma species. Journal of General Microbiology 133, 1969-1974.

Hata, D., Kuze, F., Mochizuki, Y., OhKubo, H., Kanazashi, S., Madea, S., Miwa, N. \& Mikawa, H. (1990). Evaluation of DNA probe test for rapid diagnosis of Mycoplasma pneumoniae infections. Journal of Pediatrics 116, 273-276.

Hyman, H. C., Yogev, D. \& Razin, S. (1987). DNA probes for detection and identification of Mycoplasma pneumoniae and Mycoplasma genitalium. Journal of Clinical Microbiology 25, 726-728.

Jensen, J. S., Søndergård-ANdersen, J., Uldum, S. A. \& Lind, K. (1989). Detection of Mycoplasma pneumoniae in simulated clinical samples by polymerase chain reaction. APMIS 97, 1046-1048.
Keller, G. H., Huang, D.-P., Shih, J. W.-K. \& Manak, M. M. (1990). Detection of hepatitis B virus DNA in serum by polymerase chain reaction amplification and microtiter sandwich hybridization. Journal of Clinical Microbiology 28, 1411-1416.

KleEmola, S. R. M., Karjalainen, J. E. \& Räty, R. K. H. (1990). Rapid diagnosis of Mycoplasma pneumoniae infection: clinical evaluation of a commercial probe test. Journal of Infectious Diseases 162, 70-75.

LiND, K. (1982). Serological cross-reactions between 'Mycoplasma genitalium' and $M$. pneumoniae. Lancet ii, 1158-1159.

Lind, K., LindhardT, В. Ø., Schütten, H. J., Blom, J. \& Christiansen, C. (1984). Serological cross-reactions between $M y$ coplasma genitalium and Mycoplasma pneumoniae. Journal of Clinical Microbiology 20, 1036-1043.

Peter, J. B. (1991). The polymerase chain reaction: amplifying our options. Reviews of Infectious Diseases 13, 166-171.

RaZIN, S. \& Tully, J. G. (1983). Methods in Mycoplasmology, vol. I, Mycoplasma Characterization. New York: Academic Press.

Saiki, R. K., Gelfand, D. H., Stoffel, S., Scharf, S. J., Higuchi, R., Horn, G. T., Mulurs, K. B. \& ErLich, H. A. (1988). Primer-directed enzymatic amplification of DNA with a thermostable DNA polymerase. Science $239,487-491$.

Sambrook, J., Fritsch, E. F. \& Maniatis, T. (1989). Molecular Cloning: a Laboratory Manual, 2nd edn. Cold Spring Harbor, NY: Cold Spring Harbor Laboratory Press.

Sasaki, Y., Shintani, M., Shimada, T., Watanabe, H. \& Sasaki, T. (1992). Detection and discrimination of Mycoplasma pneumoniae and Mycoplasma genitalium by the in vitro DNA amplification. Microbiology and Immunology 36, 21-27.

Shames, J. M., George, R. B., Holliday, W. B., Rasch, J. R. \& MogabGaB, W. J. (1970). Comparison of antibiotics in the treatment of mycoplasmal pneumonia. Archives of Internal Medicine 125, 680-684.

Skakni, L., Sardet, A., Just, J., Landman-Parker, J., Costil, J., Moniot-Ville, N., Bricout, F. \& Garbarg-Chenon, A. (1992). Detection of Mycoplasma pneumoniae in clinical samples from pediatric patients by polymerase chain reaction. Journal of Clinical Microbiology 30, 2638-2643.

Tully, J. G. (1989). The current enigma of Mycoplasma genitalium: new findings that affect Mycoplasma identification in the clinical microbiology laboratory. Clinical Microbiology Newsletter 11, 46.

Tully, J. G. \& RazIN, S. (1983). Methods in Mycoplasmology, vol. II, Diagnostic Mycoplasmology. New York: Academic Press.

Tully, J. G., Whitcomb, R. F., Clark, H. F. \& Williamson, D. L. (1977). Pathogenic mycoplasmas: cultivation and vertebrate pathogenicity of a new spiroplasma. Science 195, 892-894.

Tully, J. G., Cole, R. M., Taylor-Robinson, D. \& Rose, D. L. (1981). A newly discovered mycoplasma in the human urogenital tract. Lancet i, 1288-1291.

URSI, J.-P., URSI, D., IEVEN, M. \& PATtYN, S. R. (1992). Utility of an internal control for the polymerase chain reaction. Application to detection of Mycoplasma pneumoniae in clinical specimens. APMIS 100, 635-639.

Wu, D. Y., Ugozzoli, L., Pal, B. K., Qian, J. \& Wallace, R. B. (1991). The effect of temperature and oligonucleotide primer length on the specificity and efficiency of amplification by the polymerase chain reaction. DNA and Cell Biology 10, 233-238. 